\title{
Emanuel Swedenborg (1688-1772): pioneer of neuroanatomy
}

\author{
R. Shane Tubbs • Sheryl Riech • Ketan Verma • \\ Marios Loukas • Martin Mortazavi • \\ Aaron Cohen-Gadol
}

Published online: 6 April 2011

(C) Springer-Verlag 2011

\begin{abstract}
Emanuel Swedenborg is widely accredited for his religious fervor and devout dedication to his spirituality. He spearheaded the creation of what is known today as the New Jerusalem Church. However, Swedenborg also served as a prominent figure in the European Enlightenment, making noteworthy strides in the fields of mathematics and science. His acumen for science instilled in the medical world groundbreaking ideas that would forever innovate the practice of medicine. Not only did Swedenborg describe intricacies of the cerebral cortex but he also discovered the perivascular spaces, the foramen of Magendie, and the cerebrospinal fluid. He noted the importance of the pituitary gland or "arch gland" in maintaining normal neurological function. Lastly, in a period where the cortex was given no significant function, Swedenborg developed the idea of somatotopic organization, and this was almost 100 years prior to Fritsch and Hitzig. It is on the shoulders of such great pioneers as Emanuel Swedenborg that we base our current understanding of the nervous system.
\end{abstract}

R. S. Tubbs $(\bowtie) \cdot S$. Riech $\cdot$ K. Verma $\cdot$ M. Mortazavi Section of Pediatric Neurosurgery, Children's Hospital, 1600 7th Avenue South ACC 400,

Birmingham, AL 35233, USA

e-mail: rstubbs@uab.edu

M. Loukas

Department of Anatomical Sciences, St. George's University,

St. George's, Grenada

A. Cohen-Gadol

Department of Neurological Surgery, Clarian Neuroscience, Goodman Campbell Brain and Spine, Indiana University, Indianapolis, IN, USA
Emanuel Swedenborg was born in Stockholm, Sweden in 1688 (Fig. 1). He was the third of eight children born into a devoutly Lutheran family and raised by his influential father, who was a Lutheran Bishop [1,2]. At the age of 11, Swedenborg enrolled in Uppsala University, where he pursued an education in philosophy and delved into the writings of Publilius and Seneca on which he based his dissertation [1, 2, 5, 8]. Upon receiving his education, Swedenborg served on the Royal Board of Mines and on the Swedish House of Lords, but he frequently traveled to pursue scientific endeavors and to perfect his writing. On a journey to England in 1710, he explored the fields of mathematics and astronomy, meeting with lofty physicists such as Sir Isaac Newton. The knowledge he acquired in London sparked in him a rare scientific creativity in which he used to propose the construction of innovational contraptions such as submarines and flying machines [1$3,5]$. Enthralled with his scientific endeavors in England, Swedenborg spearheaded the creation of a journal entitled Daedalus Hyperboreus upon his return to Sweden [1, 2]. He assumed interest in the field of metal mining and later proposed the construction of a canal between Goteborg and Stockholm $[1,2,5]$. Similarly, he invented a mechanism for lugging boats overland for the Siege of Frederickshall. When Queen Ulrica granted his family nobility in 1719, Swedenborg became overwhelmed with Sweden's monetary issues, and to alleviate the currency dilemma, he attempted to organize a decimal-based monetary system [1, 2]. Beginning in 1734, Swedenborg developed an interest in the issues behind physical science and researched in great detail the theories of anatomy and physiology, the origin of the planets and the sun, and the mathematical aspect of mechanics. From his studies, he hoped to master the study of psychology. He then focused on the relationship of the body and the soul, which in turn sparked his 


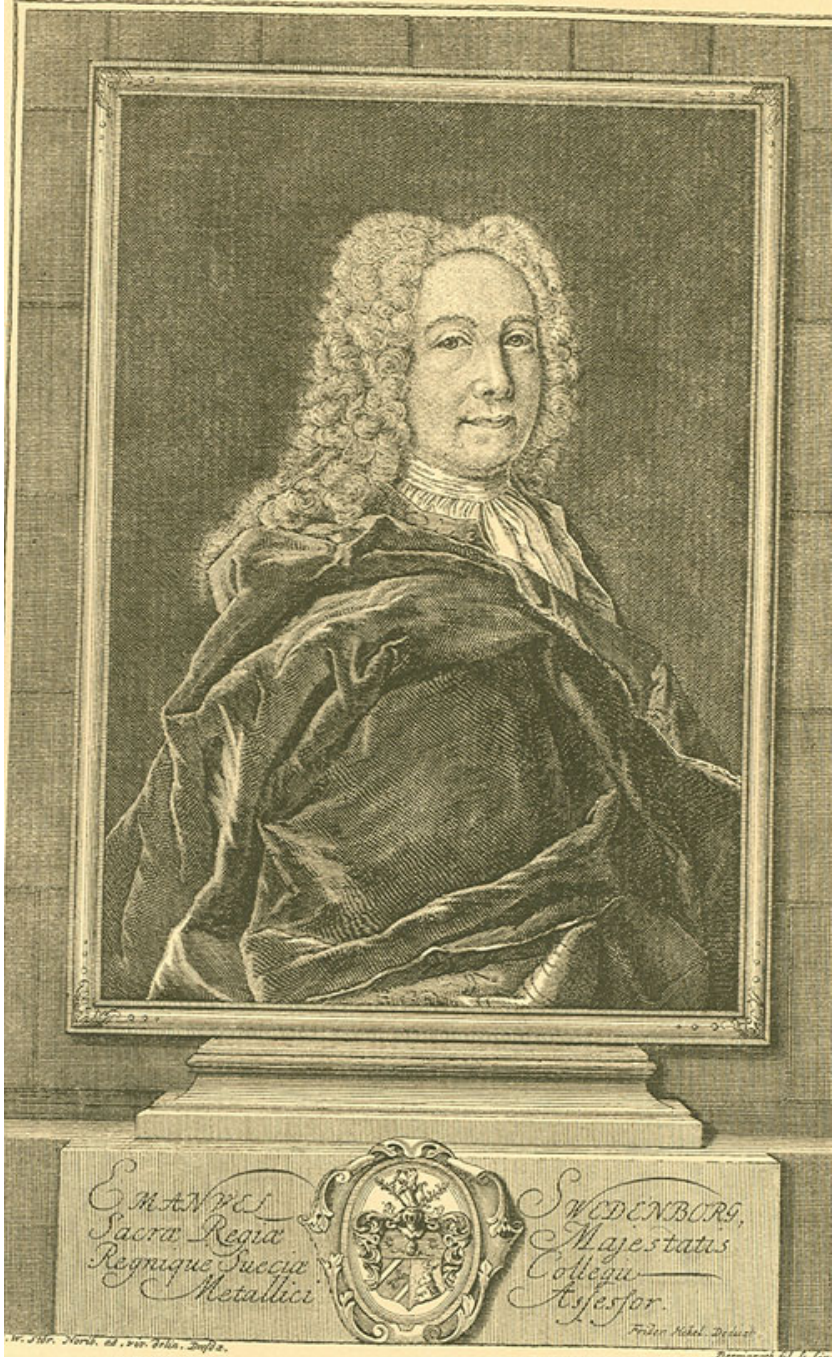

Fig. 1 Cover figure: drawing of Emanuel Swedenborg (1688-1772)

studies on the brain $[1,3]$. Later, he stepped down from the Board of Mines to focus entirely on the study of religion. Many of his peers disagreed with his fervent religious beliefs, forcing him to leave Sweden and pursue a less opulent life in London. Finally, the impoverished Swedenborg passed away in London on March 29, 1772, and his body was buried in the Swedish Lutheran church $[1,5]$.

\section{Contributions to neuroanatomy}

Swedenborg's groundbreaking neurological discoveries provided vast insight into the complex anatomy and physiology of the brain. He, however, was not accredited for his work until after his death. The majority of his publications including The Brain [9] and the The Cerebrum were not released to the public until the 1880s [3]. It was not until Max Neuburger contacted the Swedish Royal Academy for a cohesive collection of Swedenborg's work that his writings became accessible to the public. During his travels in Europe, Swedenborg wrote to his brother-in-law, describing the anatomy and physiology of the brain. In his publication Oeconomia Regni Animalis [10], later translated as The Economy of the Animal Kingdom, Swedenborg references prior scientific discoveries to develop novel insight into the brain [3]. In his writing, he acknowledged scientists including Eustachius, Ruysch, and Leeuwenhoek for their contributions and used their ideas as a basis for observation $[6,7]$.

One of Swedenborg's most astute discoveries lies in his description of the miniscule yet complex structure of the neurons within the cortex. In his paper entitled Tremulationes, he discussed the oscillation of particles through the neural process and claimed that the particles move rhythmically from the brain to the peripheral nerves and back to the brain through the center of the medulla. He claimed that the movement was spurred by wave-like palpitations of the brain and by stimuli to the sense organs. Also, he coined the term "little brains" for the cerebellula or independent units of the cerebral matter to describe the nerve cells of the cerebrum [6]. Upon examining the fibrous, chain-like configuration of the cerebellula that extends through the white matter and medulla to the spinal cord and then travels from the periphery to diverse parts of the body, he believed that the cerebellula drove various psychological states and bodily operations including sensation and movement [3]. He defied Descartes' view that the third ventricle housed the final configuration of nerve fibers and stated that the fibers originate and terminate within the cortical cerebellula [3]. If the fibers were to extend beyond the cerebellula, he explained, they would travel into the periphery. He described the means by which a stimulus traveled from each sense organ to the cortex. Overall, his discoveries regarding the cerebellula defined many of his other contributions to the study of the brain. Martin Ramstrom deemed Swedenborg's "neuron-theory" an innovative and intuitive breakthrough in the field of neuroanatomy.

In addition, Swedenborg focused on sensation governed by the nervous system. Through thorough observation and anatomical review, he distinguished the cortex as the prominent structure of the brain in which the nerve fibers terminate. He denoted the cortex as the primary control center for the sensory organs, as it innervates actions of the nerves and muscles and enables movement, cognition, imagination, judgment, and will $[2,3]$. Inside the cortex, he claimed, are cerebellula that are configured in accordance to their role in sensation; thus, the cortex is configured concisely so as to receive visual, auditory, olfactory, and gustatory sensations. Not only did Swedenborg discuss the sensory components of the cortex but he also explained the role of the cortex in governing motor activity. He claimed that the motor activity was made 
possible by the fibrous connection of the cerebellula to distinct muscle fibers. Thus, cerebellula have the ability to innervate an entire muscle or a group of adjacent muscles.

Swedenborg observed the cortex of living animals to illustrate its role in motor control. He referred to the frontal lobe as the "anterior province of the cerebrum" and claimed that this "anterior province" controlled voluntary action and intellect with an emphasis on memory and the subconscious [2]. When inflamed, Swedenborg claimed that the cerebrum lost its intellectual capabilities. Although written in approximately 1745, Swedenborg's publication, Oeconomia Regni Animalis, describing cortical contributions to muscle control was not discovered nor publicized until 1882. In this publication, Swedenborg referred to the cortex as having three distinct sections, each innervating the muscular response of a distinct portion of the body $[2,5]$. He claimed that the superior lobe of the cortex innervated the muscles of the hands and feet, while the middle lobe controlled the muscles of the abdomen and thorax. In addition, he claimed that the most inferior lobe controlled the muscles of the head and face. Thus, the muscles of the body, according to Swedenborg, were inversely related to the lobes of the cortex [1].

Some of Swedenborg's most acclaimed discoveries dealt with the hindbrain and the spinal cord. He noted that although the cortex controlled movement, the fibers of the cortex ultimately activated the muscles. Swedenborg is accredited for describing the upper and lower motor neurons and for claiming that habitual actions stemmed from a distinct motion of the cerebrum by means of the medulla [5]. He based his knowledge of habit formation from firsthand observation of the cerebral cortices of deceased animals and claimed that the subcortical gray matters such as the corpora striata were innervated during habitual action. Once an action becomes habitual, motor control shifts from the cerebrum to the corpora striata.

In addition to his findings of the cortex, Swedenborg observed the movements of decapitated reptiles and birds, claiming that not all spinal nerves originate in the same location. Instead, he stated that some spinal fibers originate in the cerebrum or cerebellum, while others originate in the oblongata or gray matters of the medulla. He claimed that the anterior roots of the spinal nerves were connected to fibers from the anterior portion of the gray matter, while fibers from the front and back portions of the gray matter constitute the posterior roots. Also, Swedenborg described various anatomical features of the brain well before they were given names by later scientists. Some of the features include the perivascular spaces, the foramen of Magendie (almost 100 years prior to Magendie's description), and cerebrospinal fluid. Interestingly, his description of cerebrospinal fluid predated the descriptions of Cotugno in 1761 by many years. He noted the importance of the pituitary gland or "arch gland" in maintaining normal neurological function [2, 4]. His observations demonstrated his keen understanding of the cerebral cortex. Lastly, Swedenborg hypothesized that the tectum was involved with vision and that the corpus callosum acted as a communicator between the left and right cerebral hemispheres.

\section{References}

1. Akert K, Hammond MP (1962) Emanuel Swedenborg (16881772) and his contributions to neurology. Med Hist 6:254.2-266.1

2. Emanuel Swedenborg (1688-1772) natural scientist, neurophysiologist, theologian (1968) JAMA 206:887-8

3. Gross CG (2009) Three before their time: neuroscientists whose ideas were ignored by their contemporaries. Exp Brain Res 192:321-334

4. Gross CG (1997) Emanuel Swedenborg: a neuroscientist before his time. Neuroscientist 3:142-147

5. Haas LF (1993) Emanuel Swedenborg (1688-1772). J Neurol Neurosurg Psychiatry 56:343

6. Ramstrom M (1911) Emanuel Swedenborg's investigations in natural science and the basis for his statements concerning the functions of the brain. J Am Med Assoc LVI:614

7. Rodgers RR (1910) Swedenborg, the philosopher and theologian. Trans Int Swedenborg Congr, pp 269-284

8. Swedenborg E (1789) A brief exposition of the doctrine of the new church (L). Hindmarsh, London

9. Swedenborg E (1882) The Brain, R.L. Tafel, (trans.-ed.), J Spiers 1,$1882 ; 2,1887$

10. Swedenborg E (1932) Oeconomia Regni Animalis, A. Clissold (trans.), Boston, 1868, in Pratt, F.H.: Swedenborg on the Thebesian blood flow of the heart. Ann Med Hist 4:434-439 